\title{
COVID-19 Induced Bilateral Lower Limb Ischemia and Visceral Infarcts
}

\author{
Spandana Narvaneni ${ }^{1}$, Sydney M. Fasulo ${ }^{2}$, Vinod Kumar $^{2}$, Balraj Singh ${ }^{2}$, Yasmeen Sultana ${ }^{3}$ \\ 1. Internal Medicine, St. Joseph's Regional Medical Center, Paterson, USA 2. Hematology and Oncology, St. Joseph's \\ Regional Medical Center, Paterson, USA 3. Infectious Disease, St. Joseph's Regional Medical Center, Paterson, USA
}

Corresponding author: Spandana Narvaneni, narvanenispandana@gmail.com

\begin{abstract}
Emerging cases of coronavirus disease 2019 (COVID-19) caused by the severe acute respiratory syndrome coronavirus 2 (SARS-COV-2) have been associated with a variety of disorders including respiratory failure, immune reactive syndrome, multiorgan failure, and hypercoagulable states. COVID-19 induces a severe global inflammatory response which can result in endothelial damage leading to hypercoagulability. Most COVID-19 cases of hypercoagulable states reported venous thrombosis. We report here a case of a 65 -yearold Hispanic male diagnosed with bilateral acute lower limb ischemia and renal infarcts secondary to a severe COVID-19 infection.
\end{abstract}

Categories: Cardiac/Thoracic/Vascular Surgery, Internal Medicine, Infectious Disease Keywords: covid19, coronavirus, thrombosis, hypercoagulability, limb ischemia, renal infarcts

\section{Introduction}

There is increasing knowledge of coronavirus disease 2019 (COVID-19) hypercoagulability with several case reports of venous thrombosis, however, there is limited information on arterial thrombosis [1]. In this case, we demonstrate the development of multiple arterial thrombotic events including renal infarcts and acute limb ischemia, as well as venous thrombi with multiple pulmonary emboli.

\section{Case Presentation}

A 63-year-old Hispanic male with no past medical history presented to the ED for shortness of breath, dry cough, and worsening fatigue for approximately one-week duration. He was hypoxic on presentation saturating $88 \%$ on room air.

Review began 12/29/2020 Review ended 01/13/2021 Published 01/19/2021

\section{○ Copyright 2021}

Narvaneni et al. This is an open access article distributed under the terms of the Creative Commons Attribution License CC-BY 4.0., which permits unrestricted use, distribution, and reproduction in any medium, provided the original author and source are credited.
Chest X-ray demonstrated bilateral hazy infiltrates, greater in the left lung field (Figure 1). Laboratory evaluation showed elevated inflammatory markers including a lactate dehydrogenase of $558 \mathrm{U} / \mathrm{L}$, ferritin of $1218 \mu \mathrm{g} / \mathrm{L}$, erythrocyte sedimentation rate $57 \mathrm{~mm} / \mathrm{h}$, C-reactive protein of $133.8 \mathrm{mg} / \mathrm{dL}$, d-dimer of 0.6 $\mu \mathrm{g} / \mathrm{mL}$, elevated liver enzymes, serum creatinine of $0.9 \mathrm{mg} / \mathrm{dL}$ which later normalized to $0.4 \mathrm{mg} / \mathrm{dL}$, and elevated white blood cell count $15,000 / \mathrm{mm} 3$. The severe acute respiratory syndrome coronavirus 2 (SARS$\mathrm{COV}-2)$ polymerase chain reaction testing was positive.

The patient was started on IV dexamethasone, ceftriaxone, azithromycin, and remdesivir. A nasal cannula at $3 \mathrm{~L}$ was not providing satisfactory oxygenation and the patient was switched to a nonrebreather at $10 \mathrm{~L}$ and then to bilevel positive airway pressure.

On day 3 of admission, the patient reported right lower extremity pain and was found to have absent dorsalis pedis and posterior tibial pulses. He was also in increased respiratory distress and tachypneic at which point he was placed on a high-flow nasal cannula. With concern for multiple arterial thrombi, a computed tomography angiogram (CTA) with iliofemoral runoff was ordered. The CTA demonstrated right middle and lower lobe pulmonary emboli, a large wedge-shaped region of hypoenhancement in the right kidney (Figure 2) and smaller wedge-shaped regions of hypoenhancement within the left mid to lower kidney representing renal infarcts. The run-off showed moderate stenosis within the origin of the right peroneal artery and segmental occlusion of the left peroneal artery (Figure 3). 


\section{Cureus}

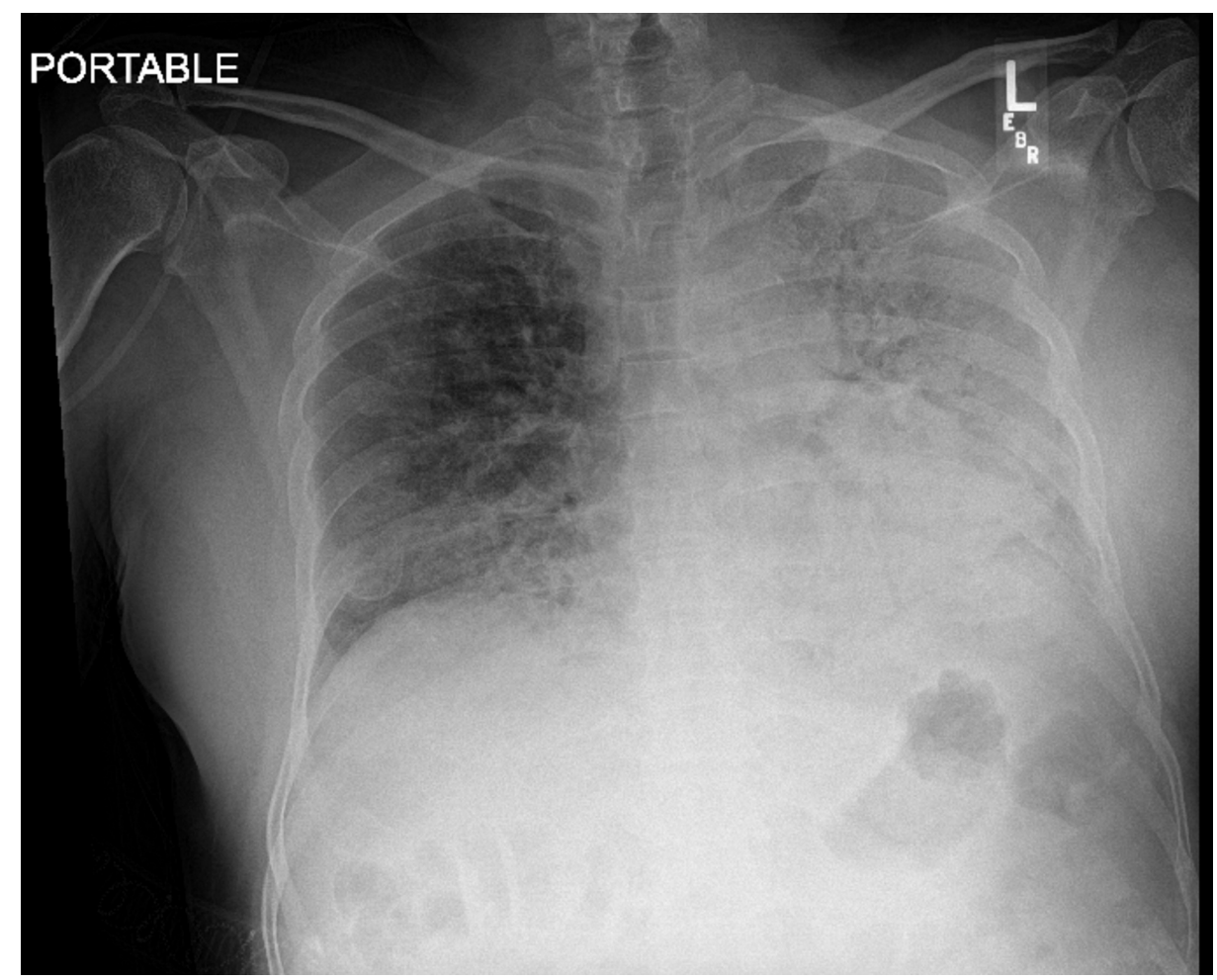

FIGURE 1: Portable AP chest X-ray demonstrating pan lobar infiltrates with more confluent opacity in the lower lungs, worse on the left than the right.

AP, anteroposterior

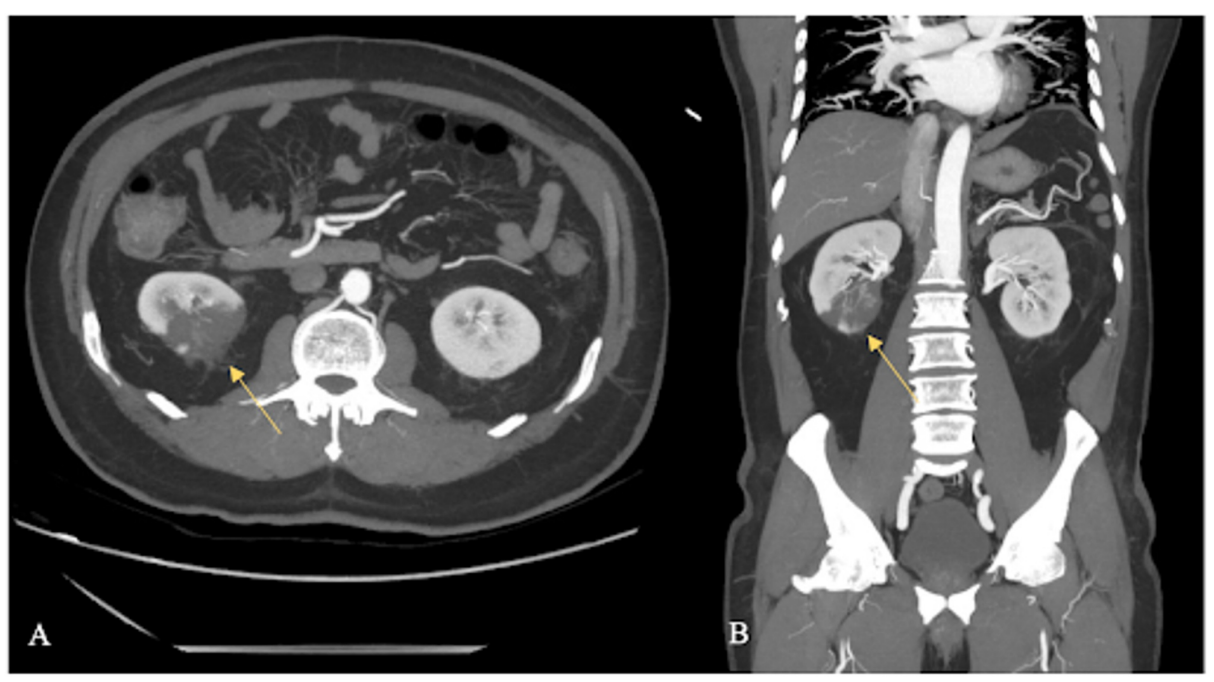

FIGURE 2: Axial image (A) and coronal image (B) from the arterial phase of a CTA demonstrating wedge-shaped regions of hypoenhancement within the lower pole of the right kidney.

CTA, computed tomography angiogram 


\section{Cureus}
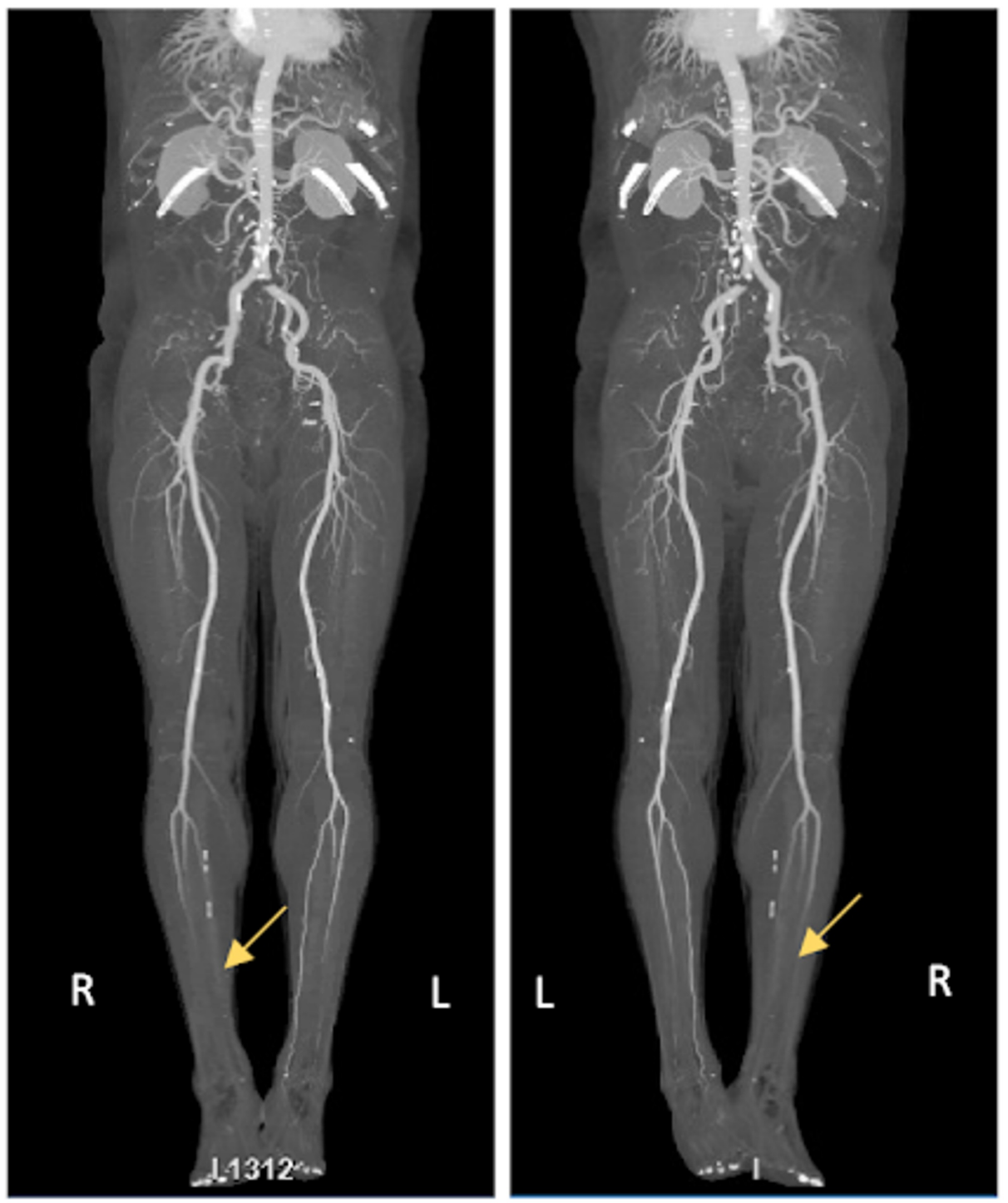

FIGURE 3: Anterior and posterior images from the CTA with iliofemoral run-off showing decreased patency of the vessels of the lower extremities, right worse than left.

CTA, computed tomography angiogram

The patient was given an IV heparin bolus and started on an IV heparin drip. The patient and family decided not to proceed with vascular surgical intervention. A 2D echo was obtained to look for a cardiac source of emboli and resulted normally. Transesophageal echocardiogram with a bubble study, though useful to rule out patent foramen ovale, was unable to be performed as the patient later became unstable and required intubation and mechanical ventilation for continued hypoxia on noninvasive modes of ventilation. No cardiac arrhythmias were observed during his hospital course.

A hypercoagulable workup was negative including anti-phospholipid antibodies; beta 2-microglobulin, anticardiolipin, and lupus anticoagulant. The patient was maintained on therapeutic anticoagulation with enoxaparin sodium.

\section{Discussion}

With the continued rise of COVID-19 infections, we continue to learn more about COVID-19 infection. Since the start of the COVID-19 pandemic, we have learned that infected patients are at increased risk for thrombotic events. A recent review of the literature showed patients with COVID-19 infections are at increased risk for deep venous thrombosis, pulmonary embolism, cerebral infarction, and visceral infarction [1-2]. 
Very little is known about the mechanism of the hypercoagulable state which develops secondary to COVID19 infections. Two proposed mechanisms are disseminated intravascular coagulation (DIC) and endotheliopathy [3]. COVID-19 infection induces a global systemic inflammatory response which releases cytokines and stimulates the coagulation cascade. The product of this cascade activation causes the formation of fibrin clots resulting in DIC. Endotheliopathy occurs when the SARS-CoV-2 virus binds to the endothelial cells of the blood vessels using the angiotensin-converting enzyme 2 receptor. The virus then replicates, causing an infiltration of inflammatory cells that induces endothelial cell apoptosis, which leads to a hypercoagulable state.

Although we continue to learn about the significant associated thrombotic events in COVID-19 patients there are still only a few case reports of COVID-19 induced renal infarction, such as Ammous et al. [3] who reported one case and Post et al. [4] who reported two cases. There are even fewer reports of COVID-19 associated limb ischemia [5-8].

\section{Conclusions}

We are reporting here a case of a 65-year-old Hispanic male with COVID-19 associated renal infarction and bilateral acute lower limb ischemia which has been only rarely reported, particularly in a middle-aged patient with no comorbidities. Awareness of the presence of arterial thrombi is an important consideration in the management and treatment of severe COVID-19 infections.

\section{Additional Information \\ Disclosures}

Human subjects: Consent was obtained or waived by all participants in this study. Conflicts of interest: In compliance with the ICMJE uniform disclosure form, all authors declare the following: Payment/services info: All authors have declared that no financial support was received from any organization for the submitted work. Financial relationships: All authors have declared that they have no financial relationships at present or within the previous three years with any organizations that might have an interest in the submitted work. Other relationships: All authors have declared that there are no other relationships or activities that could appear to have influenced the submitted work.

\section{References}

1. Abou-Ismail MY, Diamond A, Kapoor S, Arafah Y, Nayak L: The hypercoagulable state in COVID-19: Incidence, pathophysiology, and management. Thromb Res. 2020, 194:101-115.

2. Mecl AV, Paz V, Navas E, Baig I: A case of covid-19-associated acute limb ischemia . Chest. 2020, 158:A550.

3. Ammous A, Ghaffar MA, El-Charabaty E, El-Sayegh S: Renal infarction in COVID-19 patient. J Nephrol. 2020, 1-2.

4. Post A, Deurwaarder ESD, Bakker SJ, Haas RJD, Meurs MV, Gansevoort RT: Kidney infarction in patients with COVID-19. Am J Kidney Dis. 2020, 76:431-435.

5. Klok F, Kruip M, Meer NVD, Arbous M, Gommers D, Kant K: Incidence of thrombotic complications in critically ill ICU patients with COVID-19. Thromb Res. 2020, 191:145-147.

6. Anwar S, Acharya S, Shabih S, Khabut A: Acute limb ischemia in COVID-19 disease: a mysterious coagulopathy. Cureus. 2020,

7. Bellosta R, Luzzani L, Natalini G, Pegorer MA, Attisani L, Cossu LG: Acute limb ischemia in patients with COVID-19 pneumonia. J Vasc Surg. 2020, 72:1864-1872.

8. Singh B, Kaur P, Ajdir N, Gupta S, Maroules M: Covid-19 presenting as acute limb ischemia. Cureus. 2020, 